\title{
CLINICAL STUDY OF ACUTE INTESTINAL OBSTRUCTION
}

\author{
Gopalakrishna K. $\mathrm{H}^{1}$, Sudarshan $\mathrm{N}^{2}$
}

${ }^{1}$ Assistant Professor, Department of General Surgery, Mandya Institute of Medical Sciences, Mandya.

${ }^{2}$ Assistant Professor, Department of General Surgery, Mandya Institute of Medical Sciences, Mandya.

\section{ABSTRACT}

\section{BACKGROUND}

Acute intestinal obstruction is a common surgical emergency all over the world in all age groups. It is defined as interference to passage of food, liquids, contents of intestine either due to mechanical or neurological cause.

\section{METHODS}

This is a retrospective study conducted between period 2008-2012 to determine various causes for intestinal obstruction in adult population, mode of presentation, post-operative treatment, complications and its management, and to know the morbidity and mortality. The sample for study consisted of all cases of intestinal obstruction admitted during the study period diagnosed clinically and by erect X-ray abdomen or ultrasound.

\section{RESULTS}

The present study carried out in the Department of General surgery, Mandya Institute of Medical Sciences, Mandya, comprising of 20 cases between 2008 and 2012; 5 cases (25\%) affected are in the age group of 31 to 40 years and males (70\%) outnumbered females. Commonest cause for obstruction being postoperative adhesions 7 cases (45\%); most common surgery performed was adhesiolysis in our series. Predominance amongst males with adhesions, hernia and volvulus contributing to the bulk of intestinal obstructions.

\section{CONCLUSION}

Thus intestinal obstruction is the most common surgical emergency, which requires timely intervention, if not properly treated can lead to increased morbidity and mortality.

\section{KEYWORDS}

Intestinal Obstruction, Obstructed Hernias, Strictures, Strangulated Bowel, Volvulus.

HOW TO CITE THIS ARTICLE: Gopalakrishna KH, Sudarshan N. Clinical study of acute intestinal obstruction. J. Evolution Med. Dent. Sci. 2016;5(52):3405-3407, DOI: 10.14260/jemds/2016/786

\section{INTRODUCTION}

Acute intestinal obstruction is a common surgical emergency all over the world in all age groups. It is defined as interference to passage of food, liquids, contents of intestine either due to mechanical or neurological cause. The treatment of bowel obstruction was very much ill-defined and included posture, opium, purgation and administration of metallic mercury, electric stimulation and inflation of bowel with water and air. A minimal surgery was percutaneous intestinal puncture, thereby permitting gas and fluid to escape thus facilitating reduction by taxis. ${ }^{1}$ Human beings probably have suffered from acute abdominal emergencies since their first existence on earth. ${ }^{2}$ It is predisposed by various underlying causes, which are difficult to define preoperatively. ${ }^{3}$

Earlier in the century, surgery for acute intestinal obstruction was attempted to re-establish the bowel continuity before weakness and death occurred from malnutrition and dehydration. But nowadays newer developments with better understanding of pathophysiology, improvement in radiological techniques of diagnosis, fluid and electrolyte correction, much potent antimicrobials, new

Financial or Other, Competing Interest: None.

Submission 02-02-2016, Peer Review 27-02-2016,

Acceptance 29-02-2016, Published 29-06-2016.

Corresponding Author:

Dr. Gopalakrishna K. $H_{\text {, }}$

Assistant Professor,

Department of General Surgery,

Mandya Institute of Medical Sciences,

Mandya.

E-mail: drgopala566@gmail.com

DOI: $10.14260 /$ jemds $/ 2016 / 786$ surgical principles, introduction of on table lavage and resection and anastomosis have replaced staged procedure. 4

But still the mortality is more in developing countries, varies from $8-12 \%$ in recent times. Most of the mortalities occur in elderly individuals who seek late treatment and who are having associated pre-existing diseases like COPD, diabetes and IHD. 5

Therefore, early diagnosis of intestinal obstruction, proper preoperative management, proper technique during surgery and intense postoperative treatment will help to bring a gratifying result. The philosophy of "Never let the sunset or rise over a case of acute intestinal obstruction" has made early surgical intervention for acute intestinal obstruction. ${ }^{6}$

\section{AIMS AND OBJECTIVES}

- To analyse the different causes of acute intestinal obstruction in adult population.

- To analyse the anatomical, pathological nature of intestinal obstruction and age related causative factors, mode of presentation.

- To accomplish the operative, post-operative management and to anticipate the post-operative complications and their management.

- To study the rate of morbidity, mortality and causes.

\section{MATERIALS AND METHODS}

The present study was carried out in Dept. of General Surgery, MIMS, Mandya, between Sept. 2008 and 2012. All cases of acute intestinal obstruction diagnosed clinically or using X-ray and USG aged above 14 yrs. were selected. 
Investigations included routine haemogram, RBS, B urea, S creatinine, urine routine, plain X-ray erect abdomen, USG abdomen and S. electrolytes in certain cases. Emergency surgery after resuscitation was done with appropriate procedures and results are tabulated. Comparison of various factors leading to aetiology of intestinal obstruction, its aetiology, mode of presentation, management and its complications will be done.

\section{Inclusion Criteria}

All the cases of acute intestinal obstruction.

\section{Exclusion Criteria}

Patients with history of having subacute intestinal obstruction and $<14$ yrs. of age group are excluded.

\section{RESULTS AND DISCUSSION}

Age and sex in the study population.

\begin{tabular}{|c|c|c|}
\hline Age & No. of Cases & \% Percentage \\
\hline $14-20$ & 2 & $10 \%$ \\
\hline $21-30$ & 4 & $20 \%$ \\
\hline $31-40$ & 5 & $25 \%$ \\
\hline $41-50$ & 4 & $20 \%$ \\
\hline $51-60$ & 2 & $10 \%$ \\
\hline$>60$ & 3 & $15 \%$ \\
\hline Total & $\mathbf{2 0}$ & $\mathbf{1 0 0 \%}$ \\
\hline \multicolumn{3}{|c|}{ Table 1: Age Distribution } \\
\hline
\end{tabular}

Study population starting from age of 14 to those above 60 years taken into consideration with an age group of 31 to 40 years topped the list with 5 cases comprising $25 \%$.

\begin{tabular}{|c|c|c|c|c|}
\hline Age & Male & Female & Male \% & Female \% \\
\hline $10-20$ & 1 & 1 & $5 \%$ & $5 \%$ \\
\hline $21-30$ & 3 & 1 & $15 \%$ & $5 \%$ \\
\hline $31-40$ & 3 & 2 & $15 \%$ & $10 \%$ \\
\hline $41-50$ & 4 & - & $20 \%$ & - \\
\hline $51-60$ & 1 & 1 & $5 \%$ & $5 \%$ \\
\hline$>60$ & 2 & 1 & $10 \%$ & $5 \%$ \\
\hline Total & 14 & $\mathbf{6}$ & $\mathbf{7 0 \%}$ & $\mathbf{3 0 \%}$ \\
\hline \multicolumn{5}{|c|}{ Table 2: Sex Distribution } \\
\hline
\end{tabular}

In the present study in males 14 cases $(70 \%)$ were highest number as compared to females 6 cases (30\%).

\begin{tabular}{|c|c|c|}
\hline Causes & No. of Cases & $\begin{array}{c}\text { \% } \\
\text { Percentage }\end{array}$ \\
\hline $\begin{array}{c}\text { Post-operative } \\
\text { adhesions }\end{array}$ & 9 & $45 \%$ \\
\hline Bands & 4 & $20 \%$ \\
\hline Hernia & 3 & $15 \%$ \\
\hline Strictures & 2 & $10 \%$ \\
\hline Volvulus & 2 & $10 \%$ \\
\hline Total & $\mathbf{2 0}$ & $\mathbf{1 0 0 \%}$ \\
\hline \multicolumn{2}{|c|}{ Table 3: Causes Distribution } \\
\hline
\end{tabular}

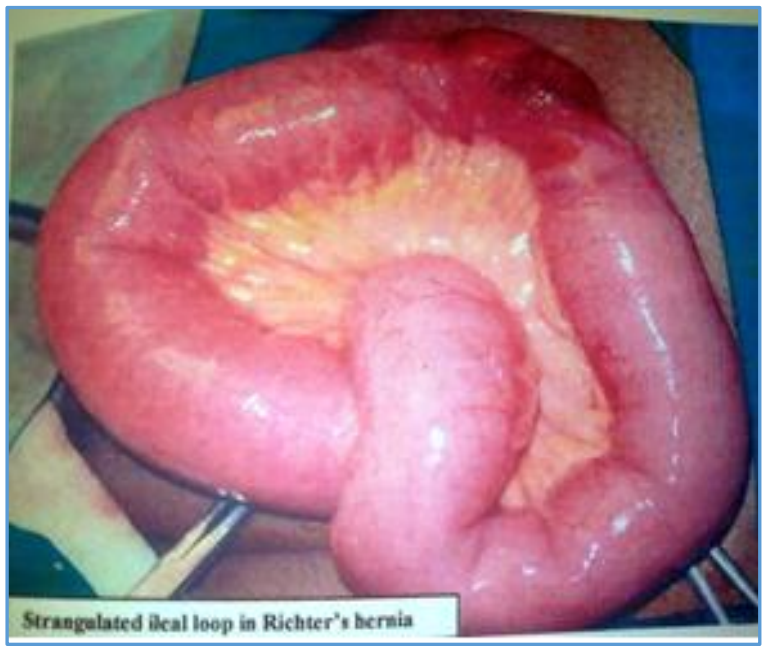

Fig. 1: Strangulated Ileal Loop in Richter's Hernia

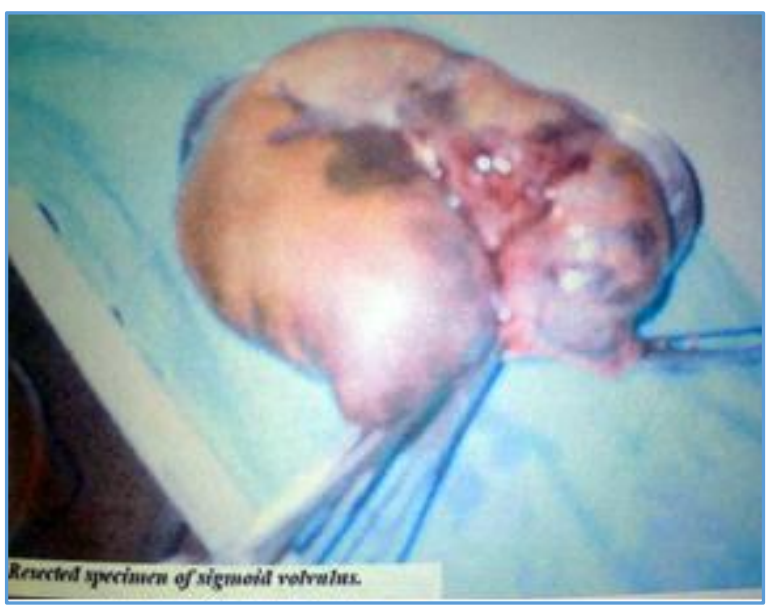

Fig. 2: Resected Specimen of Sigmoid Volvulus

\section{DISCUSSION}

It is observed from the above table that the maximum number of intestinal obstructions are seen in the age group of $31-40$ yrs. (25\%) followed equally by $21-30$ yrs. and $41-50$ yrs. (8\%), least number in age group of 14-20 yrs. and 51-60 yrs. $(3 \%)$. In the sex distribution, 14 cases of males $(70 \%)$ when compared to 6 cases of females $(30 \%)$. The influencing factors for the above post-operative adhesions and nonspecific adhesions 9 cases (45\%) followed by 4 cases of congenital bands (20\%), 3 cases of hernia (15\%) and 2 cases of volvulus and strictures (10\%).

Similar findings were observed in the studies conducted by Elli et al. $^{2}$ Menzies D and Harrold Ellis. ${ }^{3}$ Postoperative adhesions occurred in 19\% of cases with previous abdominal surgeries leading to adhesions as per Bhudharaj et al. ${ }^{4}$

C. S. Ramachandran (1982) 5 series revealed $23 \%$ of cases due to adhesions. In western studies of Brooks V. L. H. and Butler H, Cole C. J., Playforth R, Herman et al.6,7,8

In the present study 12 cases of obstruction are related to hernia (24\%), out of which 8 cases are strangulated hernia (66\%). All cases of hernia are in male patients.

Similar findings were observed by Sulfiahshakeeb (1975). ${ }^{9}$ Brooks and Butler6 reported $39.6 \%$ of strangulation and only $7.2 \%$ of gangrene.

In the present study volvulus constituted $16 \%$ of cases, Out of which 6 cases of small bowel volvulus and 2 cases of 
sigmoid volvulus. It is in consistency with Lt. Col. K. P. Rao et al. 10

Malignancy related acute intestinal obstruction constituted $6 \%$ (3 cases), out of which 2 cases are due to rectosigmoid growth and 1 case due to ileocaecal growth. The results tallied with Prascisco et al11, which are around 10$12 \%$.

In our study $4 \%$ of cases are due to intussusception ( 2 cases), both due to ileocaecal type of intussusceptions. One male and one female. Age group 30-50 followed by 3 cases, $6 \%$ due to abdominal tuberculosis. This study matched with series of Lt. Col. K. P. Rao et al 1982 (4.2\%) 10 and Sircar S et al (1996). ${ }^{12}$

All age groups are affected; majority of cases were more than 31 to 40 yrs. of age.

Male-to-Female ratio is 4:1. Pain abdomen, vomiting, constipation, distension of abdomen, tenderness over the abdomen seen in majority of cases. Hernias and past history of surgeries contribute to $60 \%$ of cases. Plain erect X-ray abdomen was the best diagnostic tool.

Intraoperative findings varied from congenital bands to postoperative adhesions. Most common surgery performed in our series is adhesiolysis followed by resection and anastomosis. Post-operative complications like infection of wound, pneumonia, faecal fistula, burst abdomen and septicaemia seen in $36 \%$ of cases.

Clinical features and presenting symptoms in the present study was pain abdomen in 50 cases (100\%), vomiting 45 cases (90\%), distension of abdomen 41 cases $(82 \%)$ and constipation in 33 cases (66\%). All the cases in present study underwent surgical management. Out of 12 cases of hernia, 4 cases underwent reduction of hernia and herniorrhaphy, 4 cases underwent omentectomy and 4 cases underwent resection and anastomosis. Adhesiolysis done in 19 cases. Derotation in 5 cases with band release and fixation in 2 cases. Out of 2 volvuli, 1 underwent sigmoidectomy with end-to-end anastomosis and transverse colostomy in another case, 1 case of ileocaecal growth ended with right hemicolectomy. Ileotransverse anastomosis done in 4 cases.

Post-operative complications like wound infection in 6 cases $(12 \%)$, chest infection pneumonia in 5 cases $(10 \%)$, faecal fistula in 3 cases (6\%), and burst abdomen in 1 case $(2 \%)$ and septicaemia in 3 cases was seen. In present study, 4 cases expired (8\%), predisposing cause volvulus - 1 case, malignancy - 3 cases which tallied with Budharaj S.N. et $\mathrm{al}^{4}$, Lt. Col. K.P. Rao ${ }^{10}$, C.S. Ramachandran ${ }^{5}$, Ade Sunkanmi et al.(13)

\section{CONCLUSION}

Thus intestinal obstruction is the most common surgical emergency, which requires timely intervention, if not properly treated can lead to increased morbidity and mortality. Timely intervention provided lifesaving in strangulation cases. Guarded prognosis in advanced stage in elderly population with early diagnosis and early referral from periphery to higher centres have resulted in good results.

\section{REFERENCES}

1. Wangensteen $\mathrm{OH}$. Historical aspects of the management of acute intestinal obstruction. Journal of surgery 1969;65(2):363-83.

2. Ellis H, Moran BJ, Thompson JN, et al. Adhesions \& related hospital readmissions after abdominal and pelvic surgery: a retrospective cohort study. Lancet 1999;353(9163):1476-80.

3. Mehzies D, Harold Ellis. Intestinal obstruction from adhesion-how big is the problem. Ann of royal col surg Eng 1990;72(1):60-3.

4. Budharaja SN. Acute intestinal obstruction in pindicherry. Indian journal of surg 1976;111-7.

5. Ramachandran CS. Acute intestinal obstruction. IJS 1982;672-9.

6. Brooks VE, Butler A. Acute intestinal obstruction in Jamaica. Surg Gynobst 1966;122(2):261-3.

7. Cole GJ. A review of 436 cases of intestinal obstruction in Ibadan. Gur 1965;6(2):151-62.

8. Playforth R Herman, James BH, Ward OG. Mechanical small bowel obstruction. Ann surg 1970;171:783-8.

9. Sulfiah Shakeeb. Intestinal obstruction. American journal of surg 1975;130:9-14.

10. Rao KP. Acute intestinal obstruction in Kumaon hill. IJS 1982;699-704.

11. Francisco, Graham RH, Lavery IC. Management and causes of large bowel obstruction. Surg clinics of north America 1997;77(6):1265-90.

12. Sircar S, Taheja VA, Kahasara U. Clinical presentation of abdominal tuberculosis - a prospective study. Jr IMA 1996;94(9):342-4.

13. Adesunkanmi AR, Agbakwuru EA. Changing pattern of intestinal obstruction in a tropical African population. East African med journal 1996;73(11):727-31. 